\title{
Determinants of Work Stress for Construction Industry Employees in Malaysia
}

\author{
Jignyasu Prafulla Joshi* \\ Graduate School of Business \\ Universiti Sains Malaysia \\ Penang, Malaysia \\ jignyasu.joshi@gmail.com \\ Lavinsaa Paramasivan \\ Graduate School of Business \\ Universiti Sains Malaysia \\ Penang, Malaysia \\ lavinsaa@gmail.com
}

\author{
Nabsiah Abdul Wahid \\ Graduate School of Business \\ Universiti Sains Malaysia \\ Penang, Malaysia \\ nabsiah@usm.my
}

\author{
Hemalatha Somu \\ Graduate School of Business \\ Universiti Sains Malaysia \\ Penang, Malaysia \\ pkv7599@gmail.com
}

\begin{abstract}
Work stress has been identified as a major factor affecting company's success because it affects the productivity and efficiency of the employees. In Malaysia, in light of industrial revolution 4.0 (IR4.0), work stress has been observed to continue happening within the construction industry even though they begin using advancement of technology to help ease employees related tasks. This study examines whether the factors suggested in the theory of Job Demand, Control and Support (JDCS) determine work stress of employees in the construction industry. A survey was carried out on a group of safety and health practitioners in the construction industry they play an essential role in enhancing efficiency on the wellbeing arrangements of the workplace. Statistical analyses carried out on the three variables, namely the, job demand, job control and job support determined work stress. The findings indicate the importance and usefulness of the JDCS theory in explaining why employees experience work stress. The findings imply the need of how IR4.0 could cope with the three determinants in their workplace; namely, to cope with their job demand as well to enable them to believe that they have all the control and support they need to perform their work without stress.
\end{abstract}

Keywords: work stress, job demand, job control, job support, safety and health practitioner, construction industry

\section{INTRODUCTION}

Stress at the workplace has become one of the main problems in the modern world and is one of the world's most common health concerns. In many industries, not to mention the construction industry, need to receive substantial attention. Work stress can be detrimental to physical and emotional reactions when the Job demand (job expectation) and job support do not correspond to the individual's abilities to keep up with the expectations of the organization. The underlying problem of work stress among safety and health practitioners at construction worksites does affect the deterioration of their performance.

The JDCS model has contributed to the field of work stress by narrowing the focus of inquiry and providing insight in understanding local context, the literature review is conducted by examining the safety and health practitioners in the Construction Industry in Malaysia. The findings from this study validate that work stress factors influenced by safety and health practitioners demands, and effects of practitioners to be in control over their job expectations. Additionally, job support determined cause for social relationship of the organization.

The study concentrated on the factors of employees who every now and then relate to, be confronted with work stress, and on how these factors interfaces in the forecast of work stress outcomes. This study will extend the body of knowledge as it is using three key influential factors such as the JDCS to examine the work stress. Altogether 400 surveys were distributed to safety and health practitioners, however, the final considered respondents were 201, represented a response rate of 53\%. The sampling frame considered personnel enrolled with the Construction Industry Development Board (CIDB).

\section{MATERIALS AND METHODS}

The study used a quantitative research method using a cross-sectional study which investigates the data collected at one point of time in an uncontrolled setting. The study method adapted an questionnaire survey. The development of the questionnaire was done through a pre-test phase. In order to test and to eliminate confusing or biased items for clarification of five experts including one academic expert (Professor) from Universiti Sains Malaysia, Penang and four industrial experts from construction companies was carried out. Six practitioners excluded from the actual respondents were then asked to evaluate the appropriateness of the items.

Pilot study was conducted using 30 respondents before the full-scale data collection. This help the researcher to get about the proposed items (questions) for the final data collection of the main study in which the questionnaire was administered to gather the desired data to inspect the relationship among the study variables. The preliminary analysis of pilot study data was tested for the reliability of scale measurements through checking the internal consistency of the variables by using Cronbach's alpha.

\section{A. Background of Studies}

Studies show that various stressors in the construction industry can induce stress for construction workers, while the stress can lead to accident [1]. Zakaria, Mansor, and 
Abdullah [2] revealed that elements such as stress, fatigue, and unsafe act have a direct effect of workplace accidents in the organization. It has been postulated the working environment of the construction industry to be detrimental as one of the most stressful occupations [3]. Attentions need to be given on safety and health practitioners in the construction industry on issues related to work stress.

IR4.0 represents adopt new technologies for a future state of fully integrated value chain thorough digitization of work processes. In the rise of IR4.0, employees would need to be empowered to increase agility since the entire organization will be interconnected and organizations will be linked to each other [4]. A study by Ozumba and Shakantu [5], on development of ICT in the construction industry in Africa suggest absence of technological innovation and executives support to be relatively prevalent in site management. In addition, the implementation of IR4.0, expects employers intervention to intensely encourage a supportive workplace environment that firmly interfaces employees with demonstrated benefits [6].

It is fundamental to comprehend JDCS as they have an essential function to maintain the work stress of safety and health practitioners whom in return are liable for wellbeing of the workplace. The safety and health practitioner routinely conduct occupational safety and health activities from planning and besides fulfilling the legal requirements. They rapidly face work stress from initial implementation phase and right through, while constantly maintaining the objectives of the organization. Safety and health practitioner comprise between different stakeholders having concern over safety and health that lead to the establishment of an occupational group described as safety and health practitioners [7].

\section{B. Current Scenario}

Work stress is a growing concern worldwide since this considerably affects employee wellbeing, organizational bottom-line and hence for the country's economy. The Malaysian Health Ministry [8] anticipated that more than 10 percent of Malaysian would agonize some form of mental health issue by the year 2020. In Malaysia, 70 percent of employers in Malaysia are facing an increasing work stress issue, this represents 5.8 million employees are affected by high work-related stress with hypertension [9, 10]. In 2016 UK's Trade Union Congress (TUC) published that stress is a major threat to workplace health, over one thousand safety representatives collected a result of trends survey.

The study gathered among UK's safety representative in 2016, revealed stress as their highest effect to workplace hazard. This is alarming pattern, since the wellbeing of safety and health practitioners is a noteworthy risk, as it would relate to the practitioners' level of ability to care for the work environment. In Malaysia, representatives are influenced by high business-related worries with 5.8 million individuals influenced by hypertension and uncovering that 70 percent of managers in Malaysia are confronting an expanding work pressure issue $[9,10]$.

Construction industry is famous due to its stress related work to the employees. The cause is due to the industry's project-based nature and the pressure of work, along with the long working hours. The conclusion is that work stress is getting worse. Previous studies have mainly focused in industrialised countries and targeted only on one individual professional group.

Construction is one of the largest industries and one of the most dangerous sectors. Previous literature suggests the job-related factors are helpful for overcoming the prevailing stress at workplace [11]. Although safety performance improvement and safety awareness in this sector have taken place, the injury rate remains one of the highest in all industries [12]. Construction employees tend to carry out work operations that expose them to safety and health risk linked to their job and generated indirectly by their coworkers [13]. Several researchers recommended that an increased control on job demand, enhanced job control and job support would enable an organization to be competent to deal the work stress among employees $[14,15]$.

In the context of the Malaysian construction industry, while giving prominence to job demand and changes of the workplace, little is known about how safety and health practitioners respond to work stress. High level of work stress can give negative effects on employees over time [16]. Work stress in the construction industry can have a significant impact on safety and health outcomes and shall be managed in the same way as other operational risk. Reported accident of construction sector in Malaysia revealed fatality is highest cases and categorized as a third highest accident rate in the sectors [17].

\section{RESULTS}

In total 400 questionnaires were distributed to the safety and health practitioners. The data collection was through electronic mail conducted over 12 weeks, (5th Feb 2019 5th Apr 2019). At the end of the survey, the data was gathered through a survey of 201 safety and health practitioners with overall average response rate of $53 \%$.

The results of data analysis revealed that job demand has significant positive influence on work stress $(\beta=0.102, p<$ $0.10)$. Therefore, hypothesis H1 was found supported. The job demand has significant negative influence on work stress $(\beta=-0.323, \mathrm{p}<0.01)$. Therefore, hypothesis $\mathrm{H} 2$ was found supported. H3 was also found supported as job support has significant negative influence on work stress at $\beta=-0.501, \mathrm{p}<0.01$. The predictive accuracy was also inspected for the model by using Stone-Geisser's Q2. The model was found to be predictively accurate as all constructs such job demand, job control, and job support explain $59.2 \%$ of the variance on employee work stress.

This study hypothesized the correlation between job demand, job control, job support, and the issue of work stress. In total all three direct hypotheses were found supported (i.e. H1: Job demand influences the relationship with work stress, H2: Job control influences the relationship work stress, H3: Job support influences the relationship work stress).

\section{DISCUSSION}

This research makes a few contributions in broadening and understanding the concept of employee work stress by persuading job related factors such as job demand, job control, and job support. For government and policymakers, 
this study stimulates the development of strategic plans to support the construction companies by focusing on work stress which is effecting the overall growth and economic contribution of these companies and hence conducive to continuing value creation in a nation's economic growth.

Employers should give top priority for measures that enhance working conditions while effecting improvement changes on activities that that lessen undesirable work stress. In the lights of the present study's findings, it can be worthy to mention that policy-makers of construction industry may focus on the safety and health strategies and implement at all organizational levels to cope up the challenges of work stress at workplace. The successful execution of safety and health policies can lead the construction companies to gain a competitive edge and enhance their contribution in the Malaysian economy.

\section{CONCLUSION}

The study aimed to test the Karasek's [18] job demandcontrol model in the context of Malaysian construction sector. This study employs the Job Demands-ControlSupport Theory (JDCS) to investigate the factors having an impact on the employee work stress. Besides, this study empirically proved that the to attain the employees' contentment at workplace, safety and health practitioners in Malaysian construction companies must consider the job demand, job control and job support elements as they have a great influence on the overall work stress. The findings of the present study validate that influencing variables of work stress in a developing economy such as Malaysia amongst safety and health practitioners in the construction industry.

The statistical findings from the theoretical framework designed for this study provide experimental support for the impact of the JDCS on employee work stress. The generalisability of the results can also be assessed by applying the proposed framework in other industrial sectors located in Malaysia. Furthermore, this study is directed only in the Malaysian construction companies, hence, other studies may employ a comparative approach which can be generalized to the blue-collar workers and as well be widening the research focus to other Southeast Asian countries to develop a comparison between Malaysia and its competitors in the region. This was a cross-sectional study where data were tabulated at a single point in time. In point of fact, the direction of causality could not be determined. It is, therefore, limiting the debates and conclusions on the general relationships between the variables of interest to be drawn.

Avenue for further study could also explore the role of moderator in the relationship of the JDCS factors relating to work stress which is scarce research. A study by SegelKarpas [19] found employment status as a significant moderator of testing the relationship of health (i.e. number of diseases) to self-awareness and between self-awareness and depressive symptoms. Thus, employment status is anticipated to moderate the relationship with work stress. Rashid and Tahir [20] proposed that employment status has an influence for organizations to manage stress at workplace. Notwithstanding, none of studies focused on the construction industry in Malaysia. Hence, future research can be carried out by extending the research framework by adding these variables.

\section{REFERENCES}

[1] Leung M Y, Chan I Y S and Yu J. "Preventing construction worker injury incidents through the management of personal stress and organizational stressors.” Accid. Anal. Prev., 48, 156-166, 2012.

[2] Zakaria N H, Mansor N and Abdullah Z. Workplace accident in Malaysia: Most common causes and solutions. Bus. and management review, 2(5), 75-88, 2012.

[3] Leung M Y, Liang Q and Olomolaiye P. Impact of job stressors and stress on the safety behavior and accidents of construction workers. J. of Management in Eng., 32(1), 04015019, 2015.

[4] Lectra. The nine pillars of industry 4.0. Retrieved from:https://www.lectra.com/en/blog/the-nine-pillars-of-industry4.0, 2016.

[5] Ozumba A and Shakantu W. "Exploring challenges to ICT utilisation in construction site management", Construction innovation, Vol. 18, No. 3, pp. 321-349. https://doi.org/10.1108/CI03-2017-0027, 2018.

[6] Aripin ID, Zawawi EM, Ismail Z. Factors Influencing the Implementation of Technologies Behind Industry 4.0 in the Malaysian Construction Industry. InMATEC Web of Conferences (Vol. 266, p. 01006). EDP Sciences.

[7] Madsen C U, Hasle P and Limborg H J. Professionals without a profession: Occupational safety and health professionals in Denmark. Safety sci., 113, 356-361.

[8] Malaysian Digest. Working to death: Recent study shows more Malaysian getting stress-related illness. Retrieved from: http://www.malaysian digest.com/, 2015.

[9] Javaid M U, Isha A S N and Ghazali Z. "Brief communication on psychosocial work environment and wellbeing in relation to job demands-resources: a study on Malaysian public health perspective," Pertanika J. of soc. sci. and humanities (JSSH), vol. 25, no. 1, pp. 39-44, 2017.

[10] The Isosceles Group. Workplace wellness assessment Malaysia, Boston, MA, USA, 2017.

[11] Hayes B, Douglas C and Bonner A. Work environment, job satisfaction, stress and burnout among haemodialysis nurses. J. of nursing management, 23(5), 588-598, 2015.

[12] Haslinda A, Saharudin S, Roslan N H and Mohamed R. Safety training, company policy and communication for effective accident management. International J. of aca. research in bus. and soc. sci., 6(9), 2222-6990, 2016.

[13] Seifi Azad Mard H R, Estiri A, Hadadi P and Seifi Azad Mard M. Occupational risk assessment in the construction industry in Iran. International J. of occ. safety and ergo., 23(4), 570-577, 2017.

[14] Dawson K M, O'Brien K E and Beehr T A. The role of hindrance stressors in the job demand-control-support model of occupational stress: A proposed theory revision. J. of org. beh., 37(3), 397-415, 2016.

[15] Brough P, Drummond S, and Biggs A. Job support, coping, and control: Assessment of simultaneous impacts within the occupational stress process. J. of occ. health psyc., 23(2), 188, 2018.

[16] Sarafis P, Rousaki E R, Tsounis A, Malliarou M, Lahana L, Bamidis $\mathrm{P}$, Niakas D and Papastavrou E. The impact of occupational stress on nurses' caring behaviors, 2016.

[17] Ab Hadi N A, Tamrin S B M, Guan N Y, How V, and Rahman R A. D8-1 Association between non-reporting of accident and contributing factors in Malaysia' construction industry. The Japanese J. of ergo., 53(Supplement2), S648-651, 2017.

[18] Karasek R A and Theorell T. Healthy work, stress, productivity, and the reconstruction of working life. New York: Basic books, 1990.

[19] Segel-Karpas D. Number of illnesses, self-perceived health, and depressive symptoms: The moderating role of employment in older adulthood and old age. Work, Aging and Retirement, 1(4), 382-392, 2015.

[20] Rashid A and Tahir I. The prevalence and predictors of severe depression among the elderly in Malaysia. J. Cross Cult. Gerontol. 30, 69-85. doi: 10.1007/s10823-014-9248-3, 2015. 